\title{
ANTI-DIABETIC AND ANTI-HYPERTENSIVE POTENTIAL OF INDIGENOUS EDIBLE PLANTS OF QATAR Tahra Elobeid ${ }^{1 *}$, Susanna Phoboo ${ }^{2}$, Kalidas Shetty²
}

\author{
${ }^{1 *}$ Human Nutrition Department, College of Health Sciences, Health Cluster, Qatar University, Doha, Qatar
} ${ }^{2}$ North Dakota State University, Fargo, North Dakota, USA

\begin{abstract}
In this study, four edible desert plants from Qatar were selected in order to analyse their phenolic bioactives and potential health benefits for managing the early stages of type 2 diabetes and hypertension using in vitro enzyme assays. High total soluble phenolics and high antioxidant activity associated with high $\alpha$-glucosidase, moderate $\alpha$-amylase, and angiotensin-converting enzyme ( $A C E$ ) inhibitory effects were found in aqueous extracts of Cynomorium coccineum whereas Glossonema edule and Malva parviflora had moderate antioxidant potential, total soluble phenolics and angiotensin converting enzyme (ACE) inhibitory activity. It is suggested that edible plants, such as Cynomorium coccineum, possess medicinal properties that have potential as diet-based solutions for combating, preventing and managing the early stage of type 2 diabetes when coupled with overall healthy life style and pharmacological management strategies. This study provides the biochemical rationale for further animal and clinical studies to understand the health benefits of edible plants of Qatar as a part of dietary strategies for type 2 diabetes management.
\end{abstract}

\section{INTRODUCTION}

Type 2 diabetes mellitus is projected to be the ' $7^{\text {th }}$ leading cause of death by 2030' (WHO 2013). Qatar is predicted to have the highest number of diabetic patients in the near future, with a reported increase of $130 \%$ by the year 2030 (Mushlin et al. 2012). Consanguinity, the incidence of which is the highest in the State of Qatar (51\%), is frequently the cause of the prevalence of many genetic disorders and other inherited adult diseases, such as diabetes (Bener et al. 2013). In this study, we analysed phenolic bioactives from four traditional edible plants from Qatar for their potential in inhibiting $\alpha$-glucosidase, $\alpha$-amylase and ACE using in vitro assay models, tota phenolic content and antioxidant potential as well as the different types of phenolic compounds and their content using high performance liquid chromatography (HPLC) These food plants were once a part of the diet of the local Qatari population but have now been largely replaced by imported provisions. Establishing the anti-diabetic potential of these local food plants would help in managing this disease if it was incorporated in the diet.

\section{RESULTS}

The total antioxidant activity and total soluble phenolics of all four edible plants of Qatar showed significantly different results as shown in Fig 1. Cynomorium coccineum had significantly higher antioxidant activity and total soluble phenolics in comparison to the other three plants. Glossonema edule had high antioxidant activity but moderate total soluble phenolics, whereas Malva parriflora and Aizoon canariense showed low antioxidant and low total soluble phenolics content. In our study, Malva parriflora or Malva parviflora had low DPPH inhibitory activity and low total soluble phenolics content. The investigation of hydroxycinnamic acids and other phenolic acids has not been previously carried out in these four species of plants. In our study, HPLC chromatogram revealed the presence of various phenolic acids, such as gallic acid, chlorogenic acid, caffeic acid, protocatechuic acid, quercetin and cinnamic acid in all the samples that were studied. Out of the four plants studied, only Cynomorium coccineum extracts inhibited $\alpha$ glucosidase and $\alpha$-amylase enzyme based on the in vitro assay model. The aqueous extract of $C$. coccineum showed very high $\alpha$-glucosidase inhibitory activity. The aqueous extracts from Cynomorium coccineum, Glossonema edule and Malva parriflora showed ACE inhibitory activity. Inhibiting ACE is considered a beneficial therapeutic approach in the treatment of high blood pressure in both diabetic and non-diabetic patients

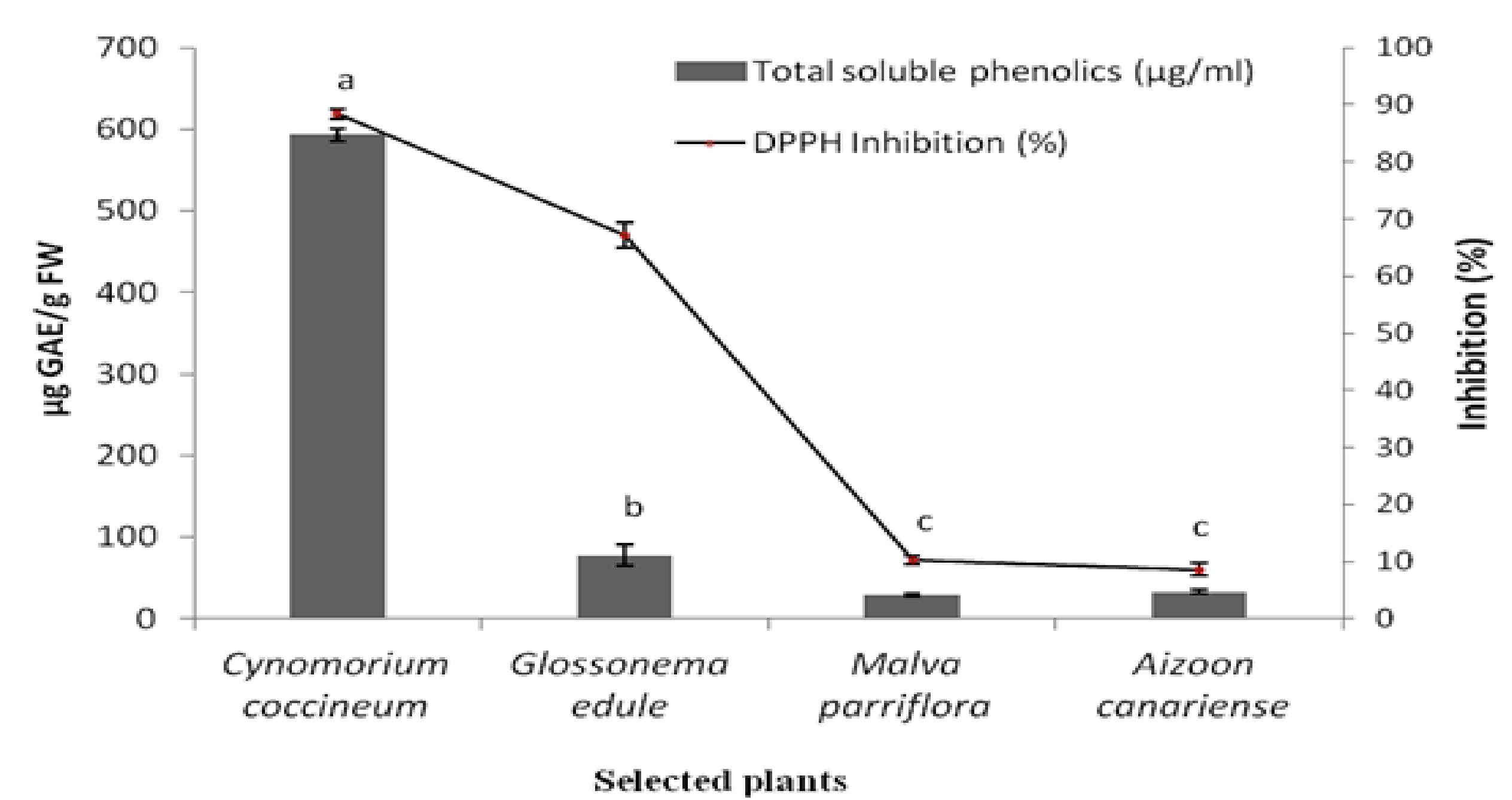

Fig 1. Total soluble phenolics ( $\mu \mathrm{g}$ GAE/ $\mathrm{g} F W$ ) and DPPH inhibitory potential (\%) of Cynomorium coccineum, Malva parviflora, Glossonema edule and Aizoon canariense.

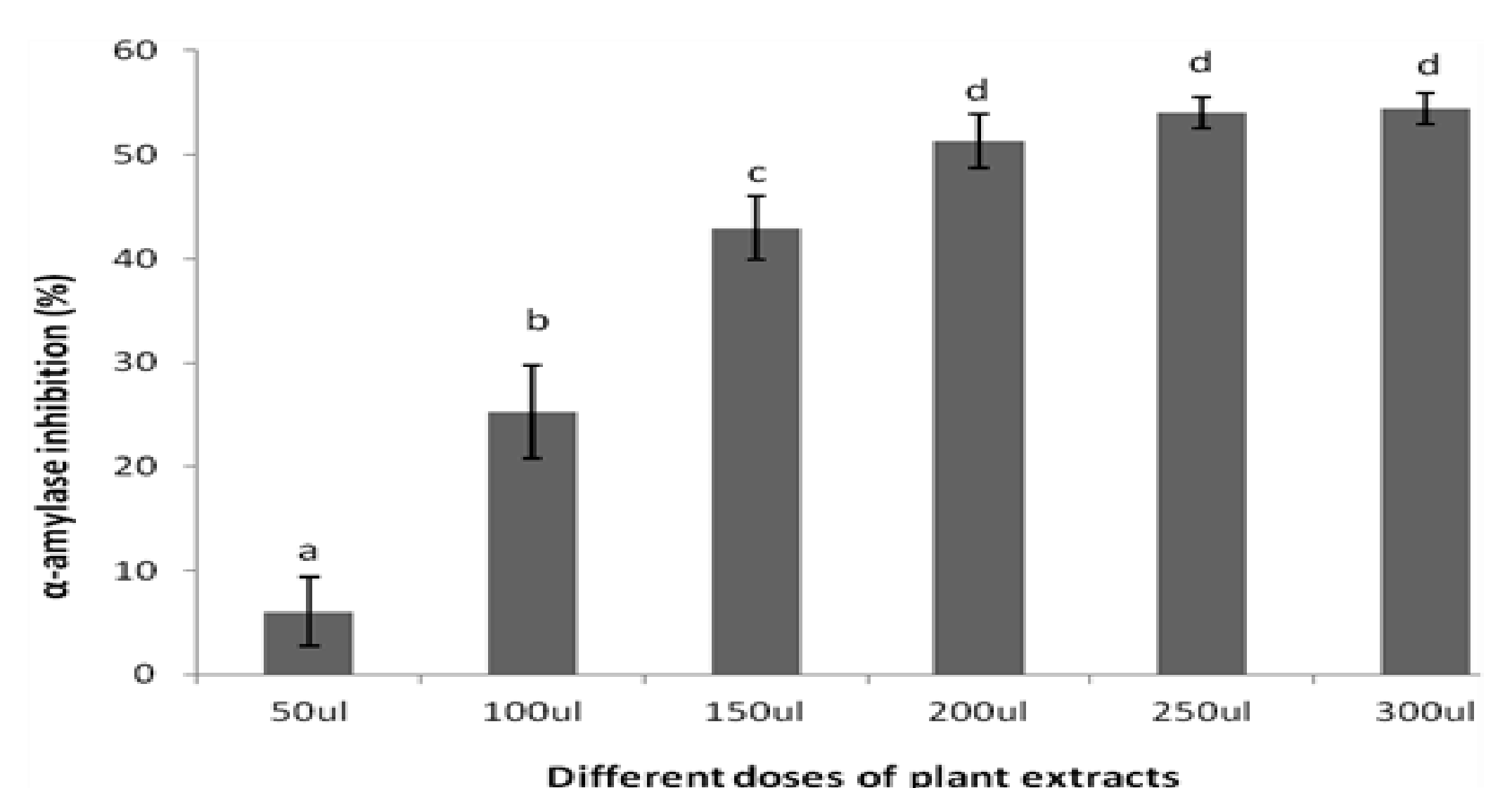

Fig 2. Alpha-amylase inhibitory potential (\%) of different doses of Cynomorium coccineum aqueous extracts. Data are mean $\% \pm$ SE values $(n=9)$. a-d $^{-\mathrm{C}}$ Columns with different letters indicate statistically significant differences among groups at $p<0.5$.

\section{CONCLUSION}

The results from this study indicate a strong possibility that Cynomorium coccineum, an edible spice source and edible food plant used in Qatar, would be potentially helpful to manage glucose and glucose-induced increased levels of ROS linked to hyperglycaemia as well as type 2 diabetes-associated hypertension. Due to its high antioxidant potential as indicated by its strong DPPH inhibitory potential, total soluble phenolics along with potent $\alpha$-glucosidase inhibitory effect, moderate $\alpha$ amylase inhibitory effect and ACE inhibitory potential, Cynomorium coccineum may be used as an edible source to prevent and manage the early stages of type 2 diabetes as part of comprehensive dietary and life style changes. Since the result of this study shows that the extracts of Cynomorium coccineum has particularly powerful $\alpha$-glucosidase inhibitory effect, it will be worthwhile to investigate this further. The other two edible plants, mainly Malva parviflora and Glossonema edule, with moderate antioxidant potential and total soluble phenolics and ACE inhibitory potential can also be useful for potentially managing hypertension and oxidation-linked vascular complications as part of comprehensive intervention solutions.

\section{REFERENCES}

Bener, A., Yousafzai, M.T., Al-Hamaq, A.O., Mohammad, AG. and De Fronzo, R. 2013. Parental transmission of type 2 diabetes mellitus in a highly endogamous population. World J. Diabetes 4, 40-46.

Kwon, Y.I., Vattem, D.V. and Shetty, K. 2006. Evaluation of clonal herbs of Lamiaceae species for management of diabetes and hypertension. Asia Pac. J. Clin. Nutr. 15,107118.

McCue, P., Kwon, Y.I. and Shetty, K. 2005. Anti-amylase, anti-glucosidase and anti-angiotensin I-converting enzyme potential of selected foods. J. Food Biotechnol. 29, 278294.

Mushlin, A.I., Christos, P.J., Abu-Raddad, L., Chemaitelly, H., Deleu, D. and Gehani, A.R. 2012. The importance of diabetes mellitus in the gobal epidemic of cardiovascular disease: The case of the state of Qatar. Trans. Am. Clin. Climatol. Assoc. 23, 193-208

WHO (World Health Organization) 2013. Diabetes. http://www.who.int/mediacentre/factsheets/fs312/en/ Worthington, V. 1993. Maltase-a-glucosidase. In: Worthington Enzyme Manual pp. 261, Freehold NJ: Worthington Biochemical Corp.

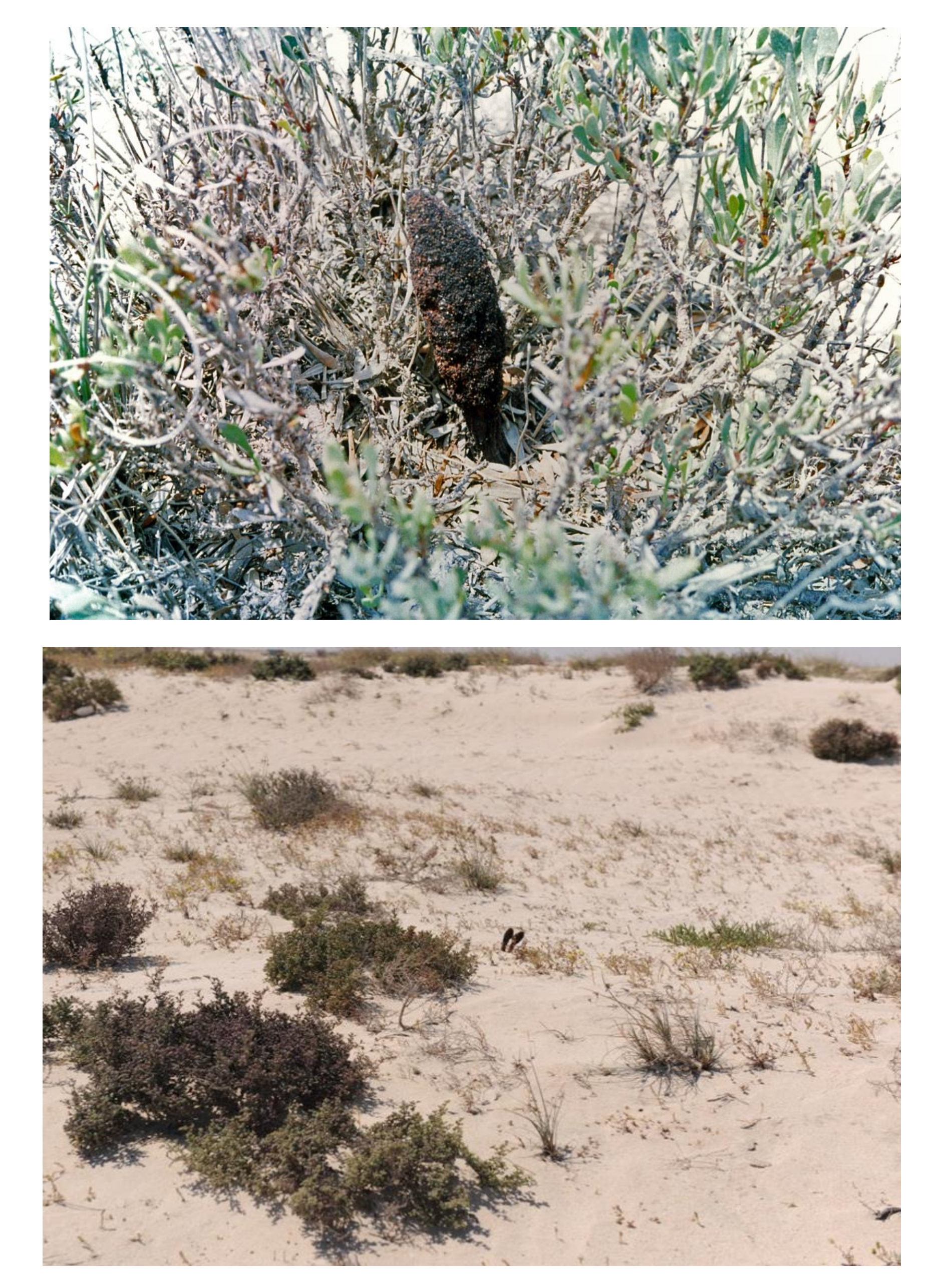

\section{METHODOLOGY}

Four indigenous plants, Cynomorium coccineum (local name: Trathuth), Aizoon canariense (local name: Jafna), Glossonema edule (local name: Yerawa), and Malva parriflora (local name: Khobeza) were collected from various locations in Qatar. Only the edible portion of the selected plants was used for sample extraction. The total soluble phenolics and ACE inhibition in all samples were determined based on previously established assays following the method used by Kwon et al. (2006) The antioxidant activity was determined by the DPPH radical scavenging method modified from Kwon et al. (2006). The alpha-amylase inhibitory activity was determined by an assay modified from the Worthington Enzyme Manual (Worthington 1993; Kwon et al. 2006). Alpha-glucosidase inhibitory activity was measured following the modified procedure described by McCue et al. (2005). HPLC was used to analyse the phenolic profiles Alpha-glucosidase inhibitory activity was measured following the modified procedure described by McCue et al. (2005). Statistical analysis was completed using one-way analysis of the variance (ANOVA) Post-hoc comparisons were carried out using LSD test or planned comparison done in SPSS version 16.0. $(p<0.05)$

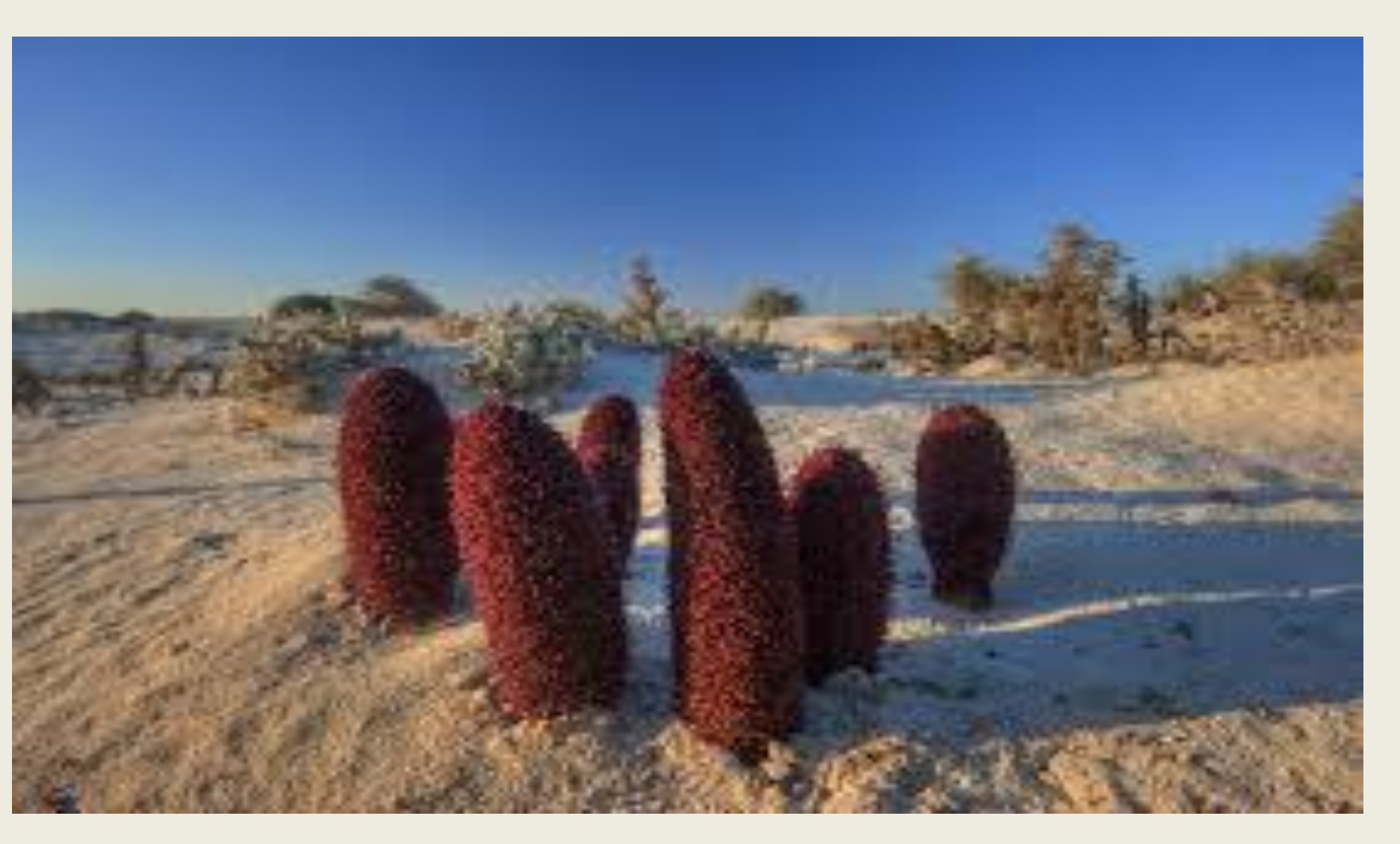

\section{ACKNOWLEGEMENTS}

This work was supported by Qatar University Research Grant

Phoboo, Susanna, Kalidas Shetty, Tahra ElObeid.. "In Vitro Assays of Antidiabetic and Anti-hypertensive Potential of Some Traditional Edible Plants of Qatar," Journal of Medicinally Active Plants 4(Vol 4 Issues 3-4):22-29. 